\title{
LA PINTURA JEREZANA EN EL SIGLO XIX
}

\author{
POR \\ ANTONIO DE LA BANDA Y VARGAS \\ Universidad de Sevilla
}

Con plena autonomía respecto del patrón provincial gaditano, se perfila la escuela jerezana de pintura, al menos desde la mediación de la centuria, durante el siglo xIx hasta el punto de constituir un interesante foco local que, con toda justicia, puede equipararse, tanto en productividad como en calidad artística, a otros regionales que jugaron un papel importante en el contexto del arte español decimonónico.

No obstante y pese a su importancia entitativa, no ha tenido, salvo en alguna que otra subasta artística reciente, la cotización que merece, por lo que su aparato bibliográfico es corto, pues, salvo la superada obra de Mariano Pescador ${ }^{1}$, se reduce a una breve mención, más de individuos que de la colectividad, en obras generales sobre arte o pintura decimonónica española o a la que, dentro del contexto andaluz o particularmente gaditano, personalmente le he dedicado 2 .

Convencido de la necesidad de difundir su conocimiento y estimular su estudio, ofrezco esta síntesis de su desarrollo histórico, no sin antes hacer constar que, especialmente a partir del historicismo, la escuela jerezana fue receptáculo, más o menos brillante según los artistas, de las corrientes más novedosas que por aquel entonces se dieron en la pintura española.

La razón primordial de la existencia de esta escuela local no es otra que el auge alcanzado por la población a causa de sus célebres negocios vinateros por lo que no es de extrañar que, dado su rico pasado artístico, florecieran a lo largo del siglo una serie de instituciones culturales que hicieron posible el nacimiento de la aludida escuela pictórica.

Fueron éstas principalmente la Real Sociedad Económica de Amigos del País, creada en 1786 y brillantemente estudiada por Manuel Ruiz Lagos ${ }^{3}$, que desde sus primeros días se interesó por el desenvolvimiento de las artes ora ocupándose de la conservación de su rico patrimonio monumental, como lo asevera el informe emitido acerca de la conservación de la Cartuja de la Defensión en 1837, ora impulsando el estudio de la delineación, como base más segura de los

\footnotetext{
1 Vid. Pescador, M.: “Los pintores jerezanos». Sanlúcar de Barrameda, 1910.

2 Vid. Banda y vargas, Antonio de la: «De la Ilustración a la actualidad», vol. VIII de la «Historia del Arte en Andalucia», Editorial Gever, S. A. Sevilla, 1991.

Ibid.: "El arte gaditano del academicismo al modernismo», en Cádiz y su provincia, tomo II, Sevilla, 1984, págs. 271-321.

Ibid.: «El arte y los museos de la provincia de Cadiz». Cádiz, 1988.

3 Vid. Ruiz Lagos, Manuel: "Historias de la Sociedad Económica de Amigos del País de Jerez de la Frontera". Jerez, 1972 .
} 

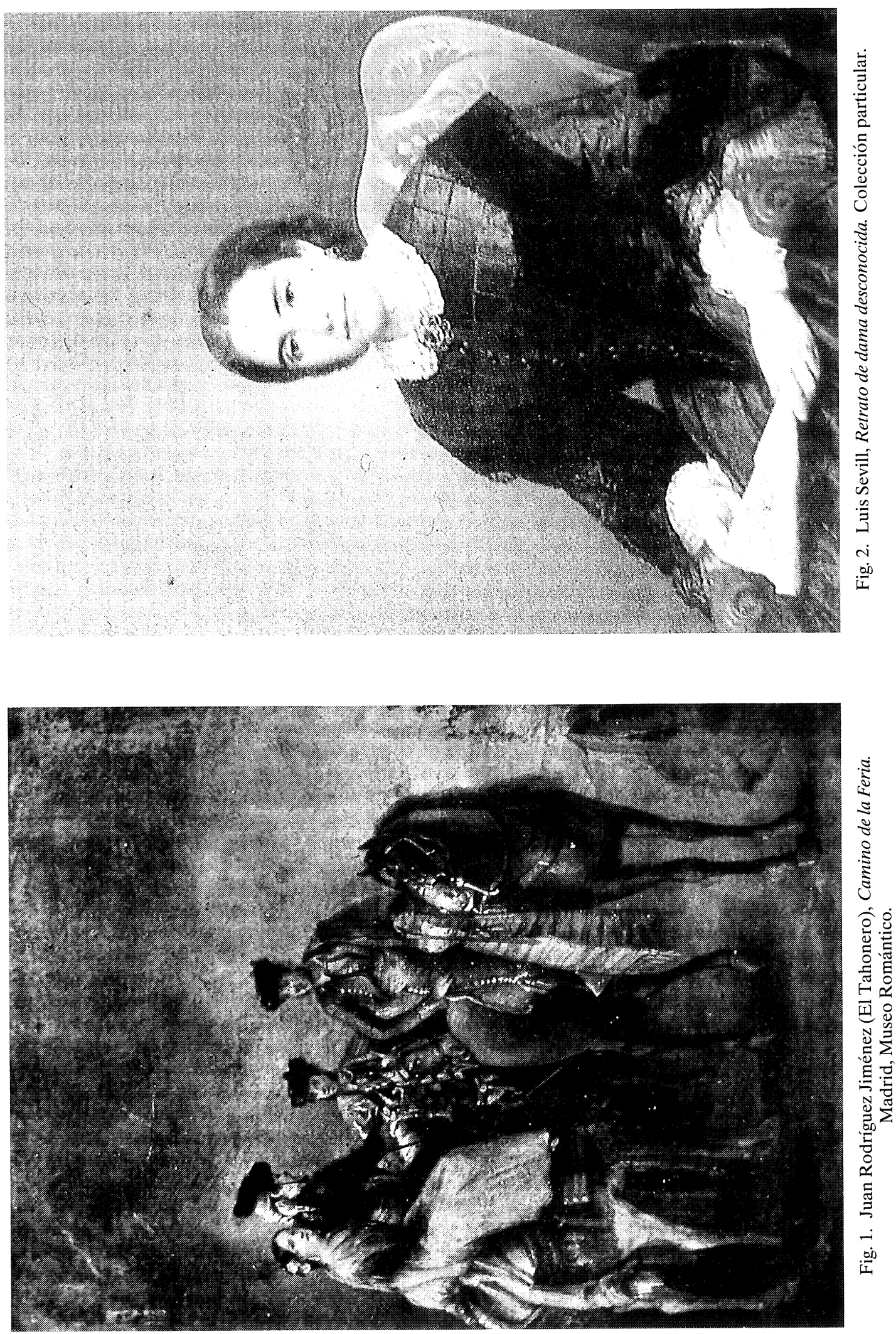
conocimientos artísticos ${ }^{4}$, así como organizando algunas exposiciones como la Agrícola e Industrial de 1856, cuya Sección XIV estuvo dedicada a las Bellas Artes, en la que se exhibieron pinturas del ya difunto Juan Rodríguez «El Tahonero" y de los entonces activos Rodríguez Losada, Bracho Murillo y Palomino.

Veinticuatro años después de esta muestra, se fundó la Academia de Bellas Artes de Santo Domingo, establecida en los altos del extinto Convento de la Orden de Predicadores, gracias al celo del prócer local don Pedro J. de Lassaletta con una clase de Dibujo del Antiguo y Ropajes costeada por los socios, cuyo alumnado era en su mayor parte artesano, que amplió sus tareas a los estudios superiores de carácter artístico con docentes de la talla de Rodríguez de Losada, al que nombró Director del Centro, Manuel Montero, Pedro Lassaletta y Fernando Reguera y una matrícula de ciento cuarenta y dos alumnos que cursaron las enseñanzas con tal aprovechamiento que, al finalizar el año escolar, pudo celebrarse una exposición de sus trabajos con tal éxito que el público visitante "salió lleno de satisfacción y orgullo al considerar el gran desarrollo que adquirió aquel centro de cultura artística» 5 .

Tal fue el posterior incremento que tomó que, en el curso 1880/1881, la matrícula alcanzó la cifra de ciento setenta y ocho alumnos, lo que motivó que la Diputación Provincial le concediese una subvención anual de dos mil pesetas anuales y otra de mil el Ayuntamiento local. Éstas hicieron posible que el profesorado, que hasta entonces había dado las clases gratuitamente, cobrase un pequeña retribución, así como el que se dotasen las de Adorno y Composición. Por último, unos nuevos Estatutos, aprobados el 1 de septiembre de 1881, le dieron mayor vitalidad; vitalidad que continuó in crescendo durante los años finales de la centuria en que tuvo como directores a los prestigiosos pintores Germán Álvarez Algeciras y Nicolás Soro Álvarez y formó artistas de la talla de Gallego Arnosa, Sánchez Barbudo y Muñoz Otero.

Al lado de la Academia hubo otros dos centros en los que se impartían enseñanzas de carácter artístico. El Ateneo Científico y Literario, fundado en 1887 y cuya interesante historia debemos a Rosa María Toribio ${ }^{6}$, en el que funcionó una activa Sección de Bellas Artes cuyo primer Presidente el mencionado Álvarez Algeciras y la Exposición de Artes e Industrias Nacionales fundada por el Marqués de Bonanza ${ }^{7}$.

Con un terreno tan magníficamente abonado, no es extraño que floreciese tan importante filón creativo cuyos orígenes más remotos hay que buscarlos en la labor del prerromántico local Juan Rodríguez Jiménez (1765/1830), pues con anterioridad no había existido una auténtica escuela local sino sólo artistas aislados, los más de regular mérito, de los que nos dan escuetas noticias tanto Pescador ${ }^{8}$ como Parada ${ }^{9}$. Éste, en cambio, tiene un lugar considerable dentro de nuestra historia pictórica al haber sido, junto con el también jerezano de nacimiento pero gaditano de identidad y filiación artística Joaquín Manuel Fernández Cruzado (1781/1856), la figura más trascendental, al menos en Andalucía, del tránsito del neoclasicismo al romanticismo al haber cultivado una pintura en la que, pese a su innegable base clasicista, se advierten claros matices románticos tanto de carácter purista como de índole casticista.

Necesitado de una monografía que dé a conocer plenamente su personalidad y obra, así como delimite esta última de la producción de su hijo, se le conoce por el apodo del tahonero o panadero, por haber desempeñado este humilde oficio en su juventud. Parece que se inició en la pintura con el religioso mercedario local P. Palma, pintor de escenas devotas anclado en el tar-

\footnotetext{
4 Vid. op. cit. en la nota anterior, pág. 25.

5 Vid. op. cit. en la nota 1, pág. 138.

6 Vid. Toribio Ruiz, Rosa María: «El Ateneo jerezano». Jerez, 1981.

Vid. op. cit. en la nota 1, pág. 138.

Vid. op. cit. en la nota 1, págs. 23-28.

9 Vid. Parada Barreto, Diego Ignacio: «Hombres Ilustres de Jerez de la Frontera». Jerez, 1875, págs. $402-406$.
} 
dobarroquismo de estirpe murillesca y autor de obras como el San Cristóbal de la Parroquia de San Miguel o de los lienzos existentes en la Casa de las Huérfanas de Jerez, con quien debió de aprender sólo los rudimentos del oficio, pero, liberado de su inicial ocupación, pasó a Cádiz en 1804 donde se matriculó en la Escuela de Nobles Artes en la que bajo la tutela de los discípulos del recién fallecido Domingo Álvarez Enciso que en ella profesaban, adquirió una sólida formación que, al unirse con sus dotes naturales, dio por resultado el que llegase a ser un notable pintor.

Establecido en Cádiz, militó durante la Guerra de la Independencia en el Batallón de Voluntarios creado por la Escuela de Nobles Artes, trabajando, al decir de Pescador ${ }^{10}$, tanto para la localidad como para Inglaterra. En 1813 fue a Sevilla donde vivió cinco años y donde decoró el presbiterio de la desaparecida Iglesia del Convento de San Agustín, pasando luego a Jerez donde permaneció hasta 1824 en que fue a Portugal. Allí vivió durante algún tiempo, realizando las pinturas que decoran el interior de la Iglesia de la Encarnación de Lisboa, merecedoras de un trabajo monográfico que las analice tanto estilística como iconográficamente, así como un telón para el Teatro de Oporto. A su regreso a España se estableció en Cádiz donde, víctima de una enfermedad nerviosa que llegó a causarle la enajenación mental, murió el 15 de noviembre del mencionado 1830.

Ecléctico por formación, supo combinar las secuelas de la tradición murillesca, aún vigente en Andalucía, con el clasicismo de corte academicista aprendido en la Escuela de Cádiz por lo que, pese a su lenguaje neoclásico, intuyó el romanticismo tanto por su colorismo cuanto por el lirismo con que trató sus asuntos históricos y por su dedicación a las escenas costumbristas. Correcto de dibujo, tiende a la plasticidad formal pero con el contrapunto de unas tonalidades fogosas y de una elevada sensibilidad.

Autor de numerosas obras, pese a lo tardío de sus comienzos, cultivó la pintura sacra, en la que claramente evidencia su murillismo, con aciertos como el Buen Pastor de la Catedral jerezana, fechado en 1822; de la Concepción de los Capuchinos y del San Luis Gonzaga de la Casa de las Huérfanas de la misma localidad. Realizó algún que otro asunto mitológico, con el lógico predominio de su componente clasicista, como el Apolo y las Musas del telón del desaparecido Teatro Principal gaditano y fue un buen retratista como lo prueban, entre otros, el del célebre arquitecto neoclásico portuense Torcuato José Benjumeda, depositado por la Real Academia de Bellas Artes de Cádiz en el Museo local, así como el de Mariscal de Campo don Martín de la Carrera. No obstante, son sus lienzos históricos y los de carácter costumbristas lo más novedoso de su producción al poner de manifiesto su inmediata proximidad al movimiento romántico.

Su conocido asunto del Marqués de la Romana embarcando a las tropas españolas en Fionia -en realidad se trata del boceto de un lienzo mayor perdido- que guarda el Museo Romántico, es el resultado de su participación en una empresa llevada a cabo por la Escuela de Nobles Artes de Cádiz que acordó perpetuar la gesta convocando un concurso público para la realización del referido cuadro; concurso que, inicialmente ganado por Fernández Cruzado, conllevó la realización de la obra por El Tahonero que nos dejó una de cierta calidad en la que preanuncia el tono lírico propio de las versiones históricas de nuestro mejor romanticismo; todo ello combinado con ciertas inexactitudes compositivas, un concepto neoclásico del dibujo y ciertas licencias de toque ya de índole plenamente románticas.

Los de carácter costumbrista, sin duda alguna la primera página del género dentro del contexto de la pintura andaluza decimonónica, son pequeños de formato, espontáneos de factura y ricos de color, así como poseen un profundo sentido popular que los hace enormemente atractivos. Obras como «El baile del farol», «De palique» o «Camino de la Feria» del Museo Romántico

$10 \quad$ Vid. op. cit. en la nota 1, pág. 24. 


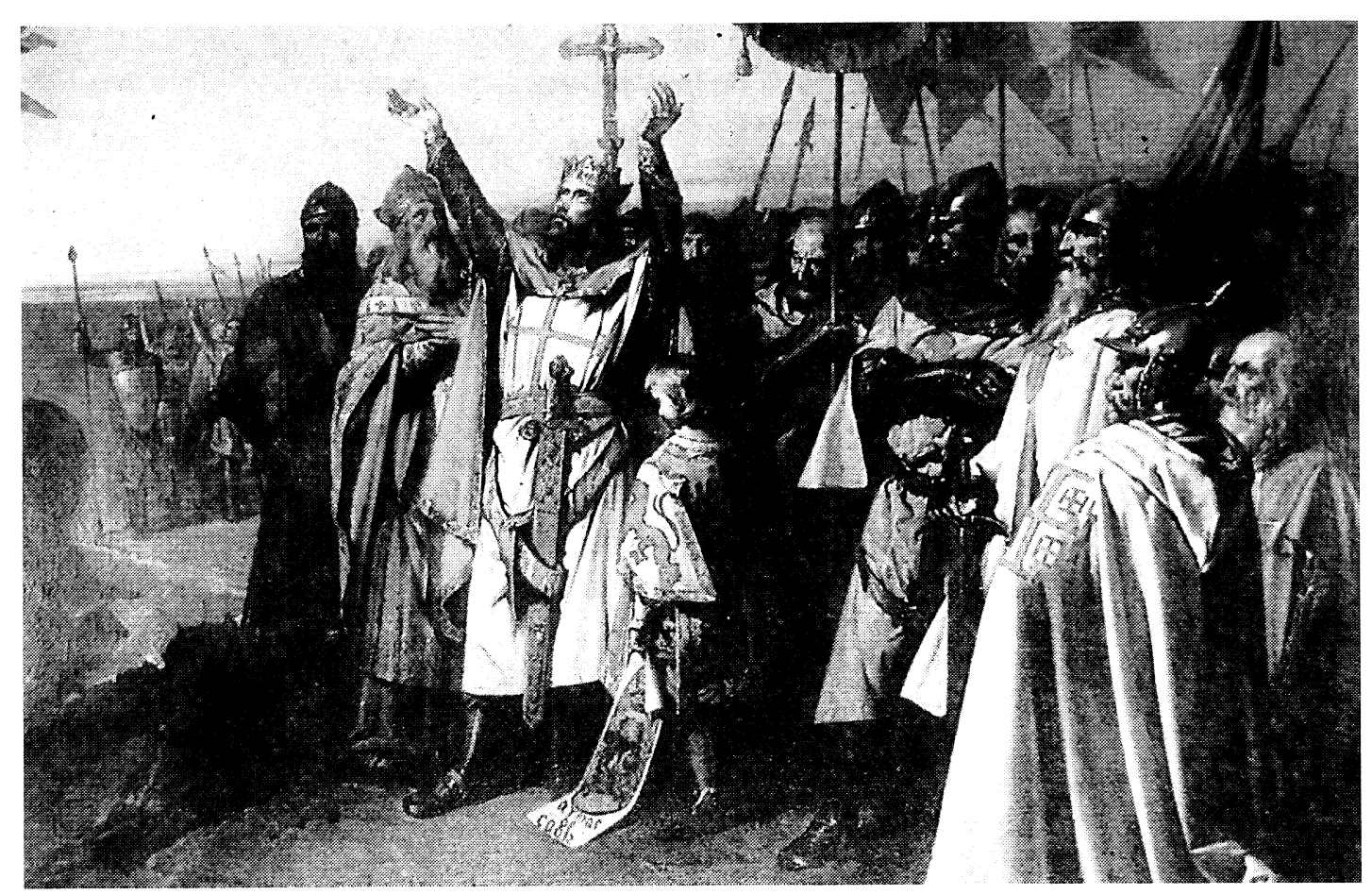

Fig. 3. José Rodríguez de Losada, La Reconquista de Cádiz. Cádiz. Ayuntamiento.

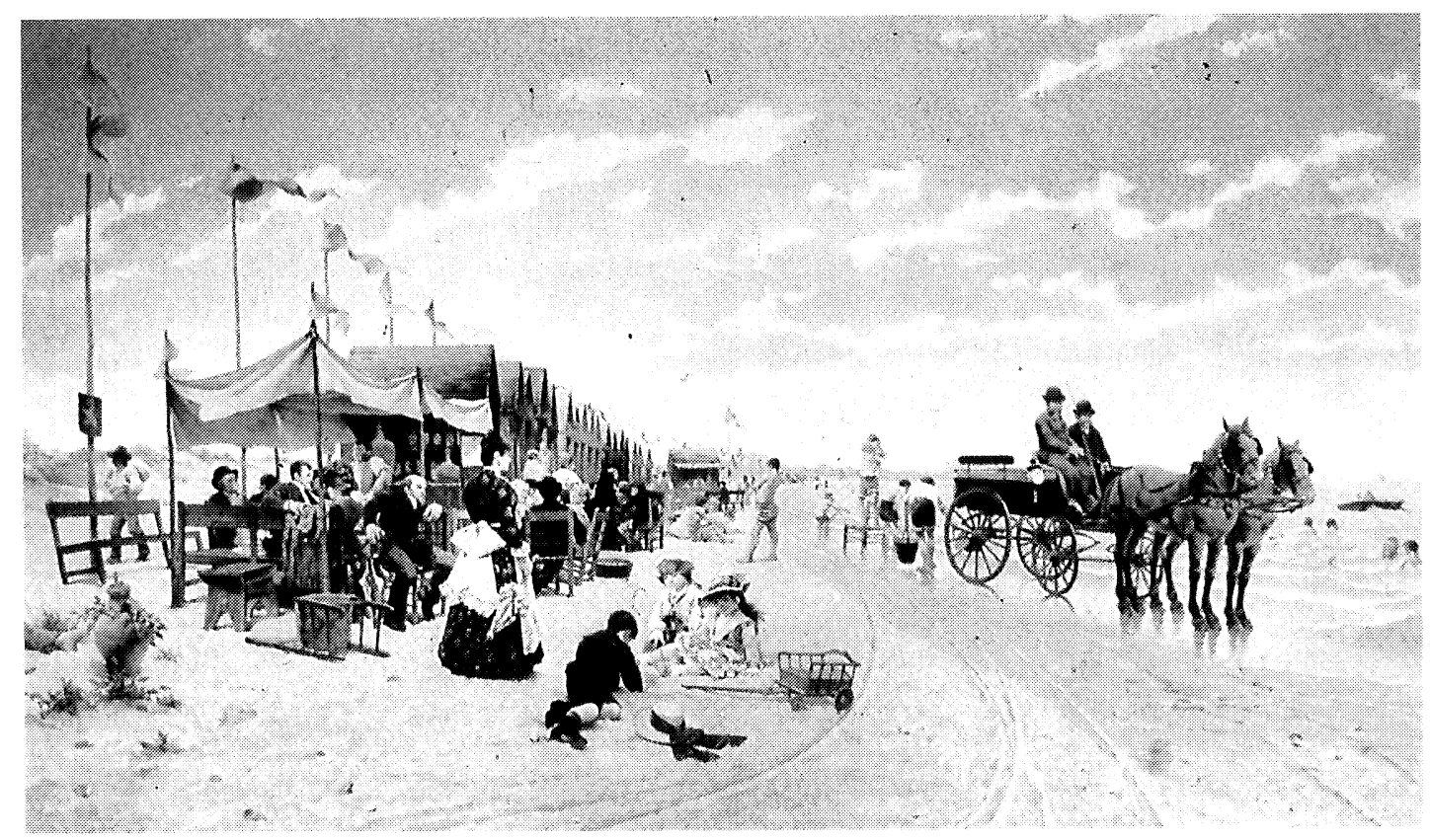

Fig. 4. Germán Álvarez Algeciras, La playa de Sanlúcar. Colección particular. 
lo atestiguan plenamente junto con las existentes en la granadina Casa de los Tiros o las conservadas en colecciones particulares jerezanas.

Discípulo suyo y lógicamente más ecléctico que él, es su hijo Juan Rodríguez García, gaditano de nacimiento pero afincado en Jerez desde los veinte años y maestro de los artistas locales de la generación posterior, que alcanzó la dignidad de Pintor de Cámara Honorario en 1856 y cuya produccion esta aún por estudiar. De él conserva el Museo gaditano un discreto lienzo del Martirio de San Servando y San Germán, en el que se aprecia la influencia paterna, pero son los retratos, casi todos de personajes de la aristocracia y alta burguesía jerezana, lo mejor de su producción, así como el género que, por su dibujismo y plasticidad formal, le acerca más a la versión purista del romanticismo.

Ésta se halla presente en la pintura jerezana, si bien bajo la modalidad ecléctica de los «los templados", en la persona de Luis Sevill, también casi desconocido y necesitado de una pequeña monografía que dé a conocer su elegante producción, al que caracterizan tanto su exquisito dibujo y elegante factura cuanto la duplicidad de influencias en que se debate su quehacer y que no son otras que el prerromanticismo de Fernández Cruzado por un lado y el estilo de Esquivel por el otro. Hábil retratista, de cuidada ejecución y aristocráticas poses a la hora de plasmar a sus modelos, cuenta con obras de la calidad de la serie de retratos familiares existentes en la Bodega de González-Byass -los mejores son los de don Manuel González Ángel y Mr. Robert Blake Byass- o los femeninos de la colección Salobral, también en Jerez de la Frontera. Artista cotizado en su tiempo, alcanzó una Medalla de Plata en la mencionada Exposición de la Sociedad Económica local del año 1858.

Dentro de este eclecticismo hay que incluir, aunque a menor altura estética, a José María Dávila, activo durante la primera mitad de la centuria, autor de un buen retrato infantil, fechado en 1846, existente en el Museo de Cádiz, así como a Álvaro Mirón Duque (m. 1876), galardonado en las Exposiciones de Jerez y Cádiz, que cultivó tanto los asuntos bélicos - «Batalla» del Museo gaditano- como el paisaje - hay dos muy logrados en la colección Quintana de Jerez- a la manera de los seiscentistas holandeses e incluso la marina.

Por último, cierran la etapa romántica una serie de aficionadas ilustres de la aristocracia y burguesía local, todas ellas concurrentes a las muestras organizadas por la Sociedad Económica, enaltecedoras, a juicio de Pescador ${ }^{11}$, "de la ilustración de su sexo y la historia de las hijas de la población", como Rosario y Carmen Rivero, Cecilia de Isasi, Francisca Sánchez Mira, Carmen Caplegari y Rosa Prendergart, que llevaron a los aludidos certamenes logradas copias de cuadros célebres -las más de asunto sacro- junto con discretos originales de escenas de género y algún que otro retrato familiar.

Ahora bien, el verdadero fundador de la escuela pictórica jerezana es el sevillano José María Rodríguez de Losada (1826/1896) no sólo por su continua residencia en la localidad, sino porque gracias a su labor docente en la Academia de Santo Domingo, creó una verdadera cadena de discípulos y seguidores que, con los lógicos cambios estilísticos propios del paso del tiempo y del cambio de mentalidad, se agruparon escolarmente en torno al mencionado Centro docente dominicano y más tarde en torno a la Escuela de Artes y Oficios que comenzó a funcionar en los inicios de la nueva centuria.

Formado en la Escuela de Bellas Artes de su ciudad natal, amplió estudios en la madrileña Academia de San Fernando pasando a Jerez, tras una interesante y fructífera etapa cordobesa, donde llevó a cabo lo más notable de su producción y donde murió, aunque sin perder el contacto con el resto de los focos artísticos bajoandaluces -fue asiduo concurrente a las Exposiciones de Sevilla y Cádiz, siendo premiado en esta última con Medalla de Oro-, así como lo hizo a

11 Vid. op. cit. en la nota 9, pág. 404. 
las Nacionales de Bellas Artes en las que obtuvo sendas Menciones Honoríficas en los años 1858 y $1867^{12}$.

Partiendo de un romanticismo casticista, cuyo mejor ejemplo es el Autorretrato con su esposa que figura en el Museo gaditano y en el que la pareja aparece vestida con traje regional, llegó a un postrer naturalismo de clara índole realista, visible sobre todo en los retratos de sus años finales, así como en alguna que otra escena costumbrista del mismo momento, pasando por la ortodoxia historicidad a la que hay que considerar como su estilo más genuino.

Dotado de una sorprendente facilidad para la composición y ejecución de sus obras, produjo una ingente cantidad de lienzos de toda clase de tamaños y de asuntos que bien puede considerársele como el "fa presto" de nuestra pintura decimonónica aunque con la funesta consecuencia de convertirse en un artista desigual que, al lado de buenos trozos de pintura, ofrece múltiples obras de convencionales, que a veces parecen estar ejecutadas con auténtico sentido comercial.

Polifacético en su producción, cultivó toda clase de asuntos, desde los sacros, donde evidencia la huella del murilismo tan usual en la época, hasta los costumbristas y la propia naturaleza muerta pasando por los históricos, que son los más abundantes y representativos de su quehacer, y el retrato; destacando por su corrección dibujística y por la teatralidad con que, casi siempre, enfocó sus composiciones, principalmente las de carácter histórico, así como por lo convencional de muchas de ellas.

Como botón de muestra de su vasta obra, mencionaré, entre las de carácter sacro, el cuadro de Ánimas del Carmen jerezano, el Santiago Matamoros de la parroquia de dicho Apóstol de la misma población, el Crucificado y los cuatro Padres de la Iglesia Latina de la Prioral del Puerto de Santa María, la Virgen del Rosario del Tenis Club ecijano y el Martirio de las Santas Justa y Rufina, hoy en el portuense Castillo de San Marcos, galardonado en la Exposición gaditana de 1862. Entre las de carácter histórico destacan, aparte el logrado conjunto del Salón de Baile del Círculo de la Amistad de Córdoba con episodios de la historia local y que tal vez sea lo mejor que hizo en este género, la Reconquista de Cádiz del Museo Municipal de la Ciudad de Hércules -existe otra interpretación del tema en el aludido castillo portuense-, La defensa de Jerez por Garci Gómez Carrillo y Fortún de Torres, varias versiones de Colón en La Rábida -una en el propio cenobio franciscano rabideño y otra en la sevillana Clínica de Fátima-, Doña Juana la Loca velando el cadáver de su esposo y La batalla de Alcolea. Murillo pintando el cuadro de Santa Isabel de Hungría, entre los de asunto literaturalizable. Los retratos de Alfonso XII (Diputación de Cádiz) y don Juan de Nepomuceno Escudero, de propiedad particular, así como, entre sus tipos populares de clara filiación realista, la Gitana que figuró en la Exposición conmemorativa del CL aniversario de la fundación Caja de Ahorros de Jerez de la Frontera ${ }^{13}$.

Otros historicistas locales son: Severino López Rearan, autor de obras discretas como «La Batalla del Guadalete», ganadora de una Medalla de Plata en la Expocisión local de 1850, "Moisés recibiendo a su familia» y «Santa Bárbara acusada por su padre», así como Domingo García Díaz, discípulo de Juan Rodríguez García y más tarde alumno de la Academia de San Fernando, que alternó el cuadro de historia, donde produjo lienzos del énfasis de "Gonzalo Gustioz contemplando las cabezas de sus hijos los siete Infantes de Lara" y "Decadencia de la Inquisición", con los religiosos - «La Oración en el Huerto" y "San Bruno en oración», presentados a la Exposición jerezana de 1856- con el retrato -muy logrado el de su hermana- e incluso con la temática costumbrista - "Verano en Andalucía» e "Interior de un palco en la Plaza de Toros»- y el paisaje.

12 Vid. Pantorba, Bernardino de: «Historia de las Exposiciones Nacionales de Bellas Artes». Madrid, 1980, pág. 471, y Banda y Vargas, Antonio de la: "Artistas gaditanos galardonados en las Exposiciones Nacionales de Bellas Artes", en Anales de la Real Academia Provincial de Bellas Artes de Cádiz», núm. 10, Cádiz, 199, pág. 91.

13 Vid. "Siglo y medio de arte gaditano» (1834/1984). Madrid, 1984, pág. 25. 
A caballo entre el historicismo y el triunfo del naturalismo está Adolfo del Águila Pimentel, docente de Dibujo en el jerezano Casino de Artesano e Industriales que cultivó el casaconismo a la manera fortuniana como lo atestiguan lienzos chispeantes al modo de "Dos majas" $\mathrm{y}$ "El robo de una flor", ejecutados con soltura de pincel y gran riqueza de tonalidades, pero es, sin duda, el pleno naturalismo el que marca el verdadero cambio estilístico de los años de la restauración alfonsina al par que el momento álgido de la escuela pictórica jerezana con la eclosión de una pléyade de artistas, formados con Rodríguez de Losada en la Academia de Santo Domingo e influenciados por Jiménez Aranda que vivió algunos años en Jerez, que, por la vía del tableautin, arribaron al naturalismo para, posteriormente, recalar en el costumbrismo realista y que, docentes la mayor parte de ellos en el Centro donde se habían formado, fueron, a su vez, los maestros de la generación novencentista.

Son éstos: José Gallegos Arnosa (1857/1917), Germán Alvarez Algeciras (1848/1912) y Salvador Sánchez Barbudo (1855/1917). El primero a quien Pescador considera «digno de ser calificado de uno de los talentos más brillantes entre los pintores españoles modernos» ${ }^{14}$, nació en el seno de una familia modesta, que deseaba fuera arquitecto, iniciándose en la pintura en la aludida Academia local para pasar luego, gracias al mecenazgo del vinatero don Guillermo Garvey, a la madrileña de San Fernando, en la que fue discípulo de don Federico de Madrazo, donde obtuvo las más altas calificaciones e incluso logró éxitos externos como el obtenido en 1877 con su cuadro "Casamiento árabe» - «que no solamente sirvió para darse a conocer como artistas, sino para adquirir nombre y reputación entre los de su época»" ${ }^{15}$ - que fue adquirido por el Estado.

Dos años después marchó a Roma, desde donde envió a la Nacional de 1884 su monumental "Botín de guerra" que fue galardonado con III Medalla en el aludido certamen ${ }^{16}$, permaneciendo allí el resto de su vida, así como obteniendo otros importantes galardones entre los que destaca la I Medalla de la Internacional berlinesa de principios de siglo.

Buen dibujante y excelente colorista, pasó del historicismo al casacón de corte fortuniano, en el que produjo lo mejor de su obra, aunque a veces llegó a tangenciar el realismo de carácter popular. Aparte las ya mencionadas, destacan entre sus más acabadas obras «En el harén», dentro de las de asunto oriental; «El niño mendigo» de una colección jerezana, dentro de las de corte realista, y «Procesión en Venecia», «La visita del Cardenal» y «Coro de monjas», dentro de los casacones.

Alvarez Algeciras, en posesión, a juicio de Pescador ${ }^{17}$, «de genio, inspiración creadora, talento artístico para percibir la belleza y habilidad técnica para realizarla, también se formó en la Academia local, de la que más tarde llegó a ser Director, completando sus estudios en las de Cádiz y Sevilla. En 1871 fue a Roma, gracias a la pensión que le concedió la Diputación gaditana, dedicándose, a su vuelta a Jerez, a la docencia artística hasta el punto de ser el maestro de la generación posterior y de crear una verdadera pléyade de discípulos a los que transmitió "su vocación por la naturaleza» ${ }^{18}$.

De exquisita pincelada y claras tonalidades, es, esencialmente, un costumbrista de temática realista y netamente andaluza aunque realizada con técnica similar al tableautin. Cantor del medio ambiente local en lienzos como «En la viña» $\mathrm{y}$ «Después de los postres», lo fue igualmente del veraneo finisecular en las playas gaditanas - «La playa de Sanlúcar», propiedad del Banco de Jerez-, de los juegos infantiles -«Niños jugando a los soldados»-, así como de escenas domésticas como "Los primeros pasos" y "La salida de Misa». A tono con su época, incidió en el monaguilismo - «En la sacristía» y en la pintura literaturalizable-, «El bufón del Rey» y «Un episodio

14 Vid. op. cit. en la nota 1, pág. 42.

15 Vid. op. cit. en la nota 1, pág. 44.

16 Vid. op. cit. en la nota 12, págs. 121 y 407.

17 Vid. op. cit. en la nota 1, pág. 62.

18 Vid. op. cit. en la nota 1, pág. 63. 

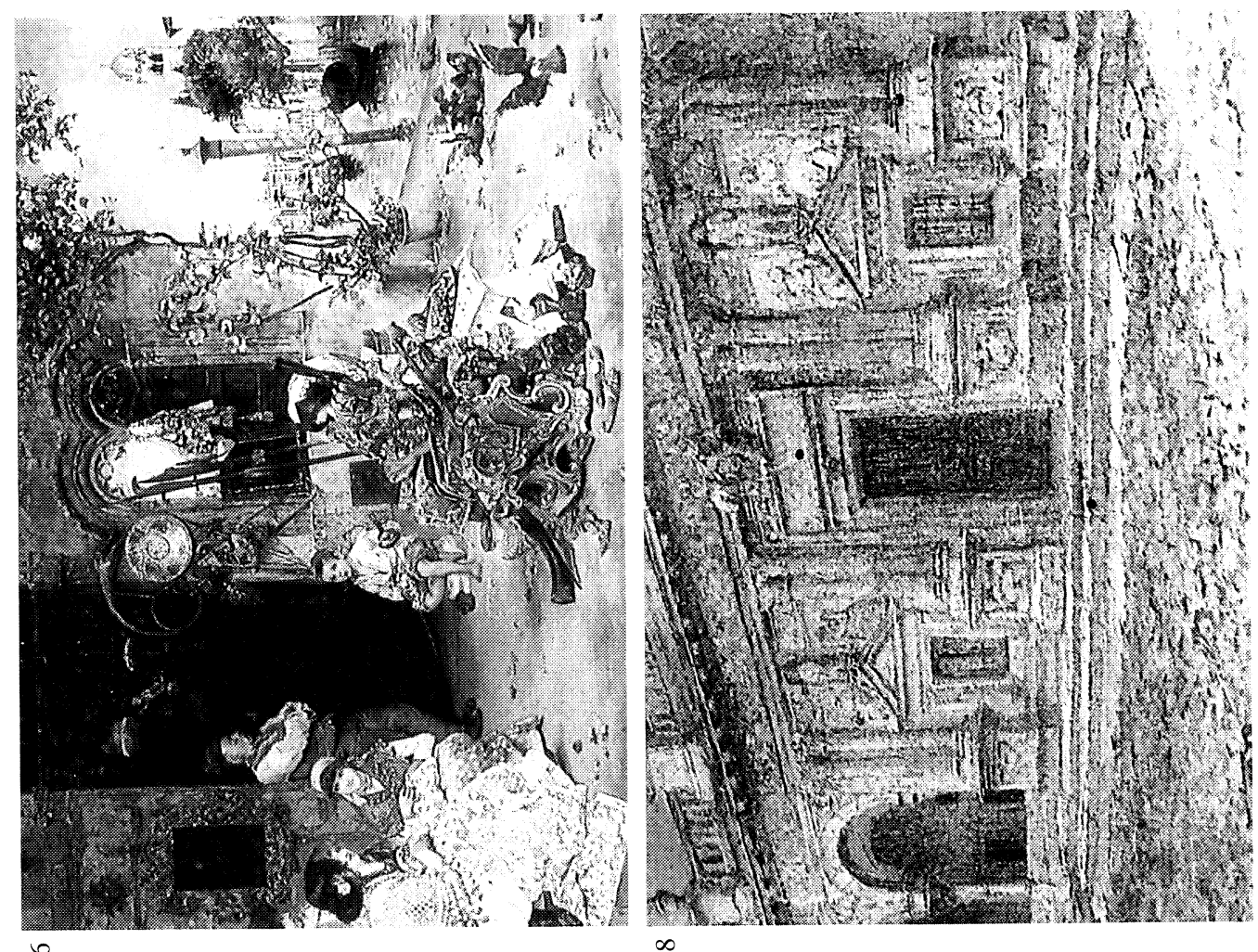

$\infty$
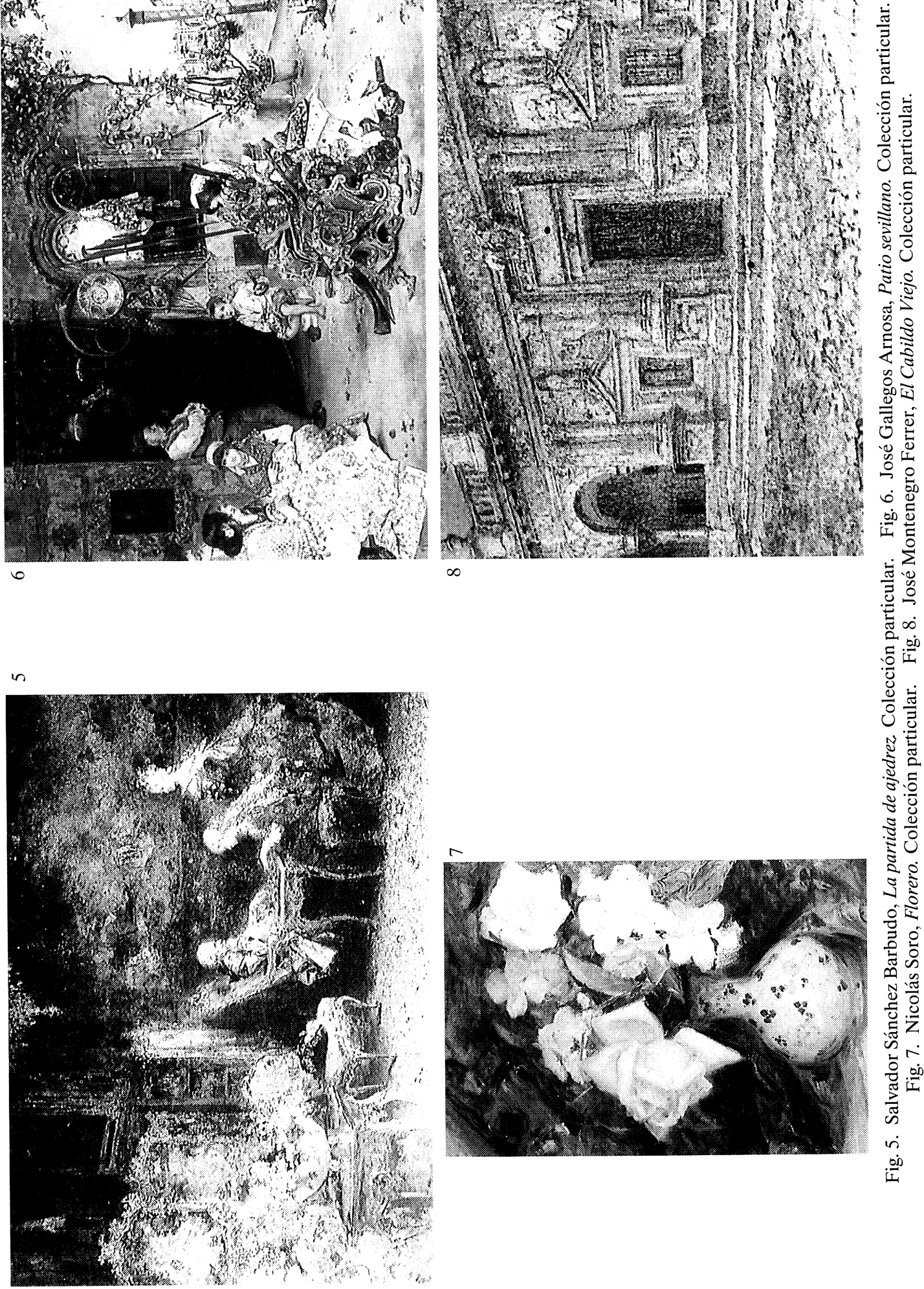
del Quijote" - aparte de ser un hábil retratista como lo corraboran los del Marqués de Misa, don José Ríos Rivera y el Obispo de Segorbe don Domingo Canuvio, los dos últimos en el Instituto jerezano Padre Coloma.

Por último, Sánchez Barbudo, que fue discípulo del sevillano Jiménez Aranda y que, gracias al mecenazgo del Marqués del Castillo, amplió estudios en Madrid para acabar sus días en Roma a la que pasó en 1882 tras haber obtenido, el año anterior, un rotundo éxito en la Exposición de Sevilla con su cuadro «Un asalto en armas» que fue premiado con II Medalla y regaló a su protector. En la Nacional de 1884 tambien fue II Medalla por su lienzo «Última escena de Hamlet» ${ }^{19}$, que adquirió el Estado; concurriendo en 1911 a la Internacional de Roma con gran éxito de crítica.

Exquisito de factura y en posesión de una cromática rica y delicada, fue un magnífico tableautinista con obras de la calidad y belleza - «en ellas encuentran su equivalente exacto todos los colores y todos los matices por exactos y complicados que sean" ${ }^{20}$ - de "La partida de ajedrez», de propiedad particular jerezana; "El Cardenal», "Sentados a la mesa» $\mathrm{y}$ "Las bodas de un Príncipe». Al haber fallecido en Italia, quedó allí gran parte de su producción, actualmente en paradero desconocido, por lo que precisa una urgente monografía que la dé a conocer en su totalidad.

Casi tangenciando el pleno realismo, se nos presenta Rafael del Villar Navarro, discípulo de Jiménez Aranda y estudioso en Madrid posteriormente, que luego fue Profesor de Dibujo en la Academia local y en cuya obra principalmente sobresale lo frío y correcto de su pincelada. Polifacético en sus asuntos, tiene algunos sacros - «La Concepción»- junto con otros de ambiente local - «Tonelería», propiedad de las Bodegas de Osborne del Puerto de Santa María-, paisajes -Pescador celebra dos en la corta semblanza que le dedica ${ }^{21}$-, bodegones - «Flores y frutos» y "Cesta de flores»-, así como retratos familiares que, al decir del mencionado crítico ${ }^{22}$, en ellos «no sólo se admira el notable parecido, sino la justeza del color».

Tambien cabe situar en la misma posición estilística a Miguel Muñoz Otero (1850/1900), alumno de la Academia local y discípulo de Jiménez Aranda en Sevilla, que pasó luego a Madrid, donde estudió en la Academia de San Fernando, así como a París, Suiza y Méjico para afincar en Roma donde murió. Paisajista y costumbrista, destaca por la corrección de su dibujo y por la belleza de su colorido; cultivando, asimismo, la temática orientalista con obras como «Un concierto en el harén" y "Odalisca».

La plenitud del realismo se enseñoreó de la escuela pictórica jerezana en el último tercio de la centuria con maestros de la talla de José Cala Moya (1850/1880), Nicolas Soro Alvarez y José Montenegro Capel (1885/1924). Cala, discípulo de Adolfo del Águila en el aula del Casino de Artesanos, trabajó en Sevilla, Madrid y Roma para afincarse durante algún tiempo en París donde obtuvo notorios éxitos que, al decir de Pescador ${ }^{23}$, fueron la consagración de su cultura artística, de sus talentos y de sus excepcionales dotes para cultivar la pintura».

Sus comienzos estuvieron en el cuadro de historia con obras como "Camilo Desmoulin arengando al pueblo en el Palais Royal»; género que alternó con las escenas costumbristas - «La vuelta al hogar»-, así como con el paisaje -a la Nacional de 1876 presentó dos de Torrelodones- en el que destacó por su facundia colorista. Más tarde afincó en el pleno realismo, aunque siempre con temas costumbristas, que alternó con buenos retratos como, por ejemplo, el de don Ángel Fernández de los Ríos.

\footnotetext{
19 Vid. op. cit. en la nota 12 , págs. 121 y 478

20 Vid. op. cit. en la nota 1, pág. 55.

21 Vid. op. cit. en la nota 1, pág. 110.

22 Vid. op. cit. en la nota 1, pág. 109.

3 Vid. op. cit. en la nota 1, pág. 85.
} 
Soro, zaragozano de nacimiento e influenciado por el sevillano Gonzalo Bilbao, llegó a Jerez como docente de la Escuela de Artes y Oficios, de la que llegó a ser Director, vinculándose totalmente con el ambiente bajoandaluz. Buen dibujante y hábil colorista, creó una abundante obra, merecedora de algunos galardones entre los que destaca la Mención Honorífica alcanzada en la Nacional de $1906{ }^{24}$, con escenas de género - «Saliendo de Jerez por la Alcubilla», de propiedad particular-, logrados tipos populares - «Muchachas» y "Gitanilla»-, así como especialmente bellas naturalezas muertas, entre las que principalmente destacan las de carácter floral.

Finalmente, Montenegro, excesivamente valorado en los ambientes artísticos locales, que, dotado de buenas cualidades, las dilapidó en aras de una excesiva productividad y de una evidente comercialización. Creador de una pintura de colorido agradable y de toque algo impresionista, pasó de las escenas realistas de carácter local a las veduttas jerezanas, que prodigó en abundancia, del tipo de "Portada de San Miguel» y "El Cabildo viejo», de propiedad particular.

Maestros menores de este momento son: Manuel González Agreda, José Camacho González y Manuel Parada Barreto. El primero, de aristocrática familia local, se formó en Jerez con Rodríguez de Losada y en Sevilla con Jiménez Aranda, marchando luego a París donde amplió estudios en la célebre Academia Julien. En posesión de un buen oficio, cultivó el realismo de carácter social - "Mendigo" y "Señorita modelo" - con el que obtuvo algunos galardones como las Menciones Honoríficas alcanzadas en las Nacionales de 1904 y 1906 25; las escenas castizas - "Muchachas de pueblo» y "Pelando la pava»-, así como estudios de tipos populares - "Una gitana"-, paisajes -tiene uno excelente de los pinares de Puerto Real-y acertados retratos como los de su progenitor, su maestro Rodríguez de Losada y don Juan Sánchez, este último en el Paraninfo del Instituto Padre Coloma.

Camacho (1846/1919), formado en Sevilla con Eduardo Cano y luego docente en la Academia jerezana, destaca por sus óptimas dotes dibujísticas, de las que hace gala en sus obras, al igual que por lo rico y variado de su cromática. Polifacético en su producción, gustó de las escenas de género - "Vendedor de frutas» y "Arreglando el altar»-, que trató con precisión de miniaturista, así como del bodegón, como lo atestigua el excelente que se exhibe, con el título de "Florero", en el Museo gaditano.

Finalmente, Parada Barreto (1842/1915) es un paisajista de veraz realismo -son varios los motivos jerezanos que se conservan en colecciones particulares de la localidad-, así como un hábil retratista que trabajó para la aristocracia y para la burguesía jerezana y al que hay que considerar como la figura puente al novecentismo, que tuvo también un notable desarrollo en esta escuela, como atestiguan los nombres de Gregorio Lloret Linares, Juan Comba y la propia María Luisa Puiggener, entre otros.

\footnotetext{
24 Vid. op. cit. en la nota 12, págs. 196 y 485.

25 Vid. op. cit. en la nota 12, pág. 414.
} 